\title{
Investigation of Non-Newtonian Fluids Flow Behavior in A Double Step Expansion Channel: Part 2
}

\author{
Ahmed A. Ouda , Khudheyer S. Mushatet and Qais A. Rishack \\ Computer Sciences Department, Computer Sciences and Mathematics College, Thi-Qar University, Al-Nasiriya, Iraq, ouda1978@gmail.com \\ Mechanical Engineering Department, Engineering College, Thi-Qar University, Al-Nasiriya, Iraq, khudheyersalim@gmail.com \\ Mechanical Engineering Department, Engineering College, Basra University, Basra, Iraq, dr.qais_abd@yahoo.com
}

\begin{abstract}
A numerical investigation to study the behavior of the turbulent non-newtonian flow through a channel from two expansions with constant heat flux at the lower wall is calculated. This behavior predicted for Reynolds number from 16000 to 100000 and for the range of power law index from 0.4 to 1.6 . The distance ratio between the two expansions is varied from 1 to 6 with expansion ratio from 1.5 to 3 and aspect ratio from 1 to 4 . These results are obtained by using ANSYS FLUENT 15.0. The results illustrate the effect of the first expansion on the second expansion and the variation of the reattachment length and Nusselt number. These results gave an idea about the ability of the step distance to control the whole flow structure.
\end{abstract}

Keywords - double expansion channel, non-newtonian fluid flow, sudden expansion, turbulent.

Nomenclature

\begin{tabular}{|c|c|c|c|c|c|}
\hline Symbol & Definition & SI Units & Symbol & Definition & SI Units \\
\hline$\dot{\gamma}$ & Shear rate & $1 / \mathrm{s}$ & $\mathrm{K}$ & Consistency index & $\mathrm{kg} / \mathrm{m} \cdot \mathrm{s}^{\mathrm{n}}$ \\
\hline$v$ & Kinematics viscosity $(\mu / \rho)$ & $\mathrm{m}^{2} / \mathrm{s}$ & $\mathrm{n}$ & Power-law index & - \\
\hline$\Gamma$ & Diffusion coefficient & - & $\mathrm{Nu}$ & Nusselt number & - \\
\hline$\phi$ & Generalized variable & - & $\mathrm{Nu}_{\mathrm{av}}$ & Average Nusselt number & - \\
\hline$\tau$ & Shear stress & $\mathrm{N} / \mathrm{m}^{2}$ & $\mathrm{P}$ & Pressure & $\mathrm{Pa}$ \\
\hline$\tau_{\mathrm{w}}$ & Wall shear stress & $\mathrm{N} / \mathrm{m}^{2}$ & $q^{\prime \prime}$ & Heat Flux & $\mathrm{W} / \mathrm{m}^{2}$ \\
\hline$\tau_{\mathrm{y}}$ & Yield stress & $\mathrm{N} / \mathrm{m}^{2}$ & $\operatorname{Re}$ & Reynolds number & - \\
\hline$\theta$ & Dimensionless Temperature & - & $\mathrm{T}$ & Temperature & $\mathrm{K}$ \\
\hline$\mu$ & Dynamic Viscosity & $\mathrm{N} \mathrm{s} / \mathrm{m}^{2}$ & $\mathrm{u}$ & Velocity in $\mathrm{x}$-direction & $\mathrm{m} / \mathrm{s}$ \\
\hline$\rho$ & Density & $\mathrm{kg} / \mathrm{m}^{3}$ & $\mathrm{U}$ & Bulk inlet velocity & $\mathrm{m} / \mathrm{s}$ \\
\hline $\mathrm{A}$ & Cross-sectional area & $\mathrm{m}^{2}$ & $\mathrm{~V}$ & Velocity in y-direction & $\mathrm{m} / \mathrm{s}$ \\
\hline $\mathrm{C}_{\mathrm{f}}$ & Skin friction coefficient & - & $\mathrm{W}$ & Velocity in z-direction & $\mathrm{m} / \mathrm{s}$ \\
\hline $\mathrm{C}_{\mathrm{p}}$ & Specific heat capacity & $\mathrm{J} / \mathrm{kg} . \mathrm{K}$ & W & Channel width & $\mathrm{m}$ \\
\hline $\mathrm{D}_{\mathrm{h}}$ & Hydraulic diameter (4A/Per.) & $\mathrm{m}$ & $\mathrm{x}$ & Streamwise coordinate & $\mathrm{m}$ \\
\hline $\mathrm{h}$ & Step height & $\mathrm{m}$ & $\mathrm{y}$ & Transverse coordinate & $\mathrm{m}$ \\
\hline $\mathrm{H}_{\text {in }}$ & Duct height upstream of the step & $\mathrm{m}$ & $\mathrm{Z}$ & Span wise coordinate & $\mathrm{m}$ \\
\hline $\mathrm{H}_{\text {out }}$ & Duct height downstream of the step & $\mathrm{m}$ & $\Delta_{\mathrm{ij}}$ & Rate of deformation & $1 / \mathrm{s}$ \\
\hline
\end{tabular}

k Thermal conductivity W/m.K

\section{INTRODUCTION}

An expanding section of a channel fluid-carrying is called a sudden expansion, in which the kinetic energy of the fluid is converted to static pressure head. This geometry is encountered in multiple equipment's [1]. One of the industrial important applications is to use it in combustion chambers of an aircraft and head box of the paper pulp machine. Understanding the flow structure of a sudden expansion needs more research work. Many attempts to modify or improve the flow structure have been performed. Up to date, the double step sudden expansion does not covered by a large number of studies. Therefore, the authors here try to submit a three- 
dimensional detailed study for double step expansion of non-newtonian turbulent flow is to be investigated.

Many researchers studied the sudden expansion or nonnewtonian fluids flow such as:

Podolsak et al. [2] determined dynamic shear properties of three distinctive non-Newtonian fluids, aiming to investigate their flow behavior through tube with abrupt contractions and expansions by using modified Quemada model. He found that the Corrections of inertial, and entrance effects from Newtonian results can be approximately applied to non-Newtonian results. Manica et al. [3] tried to simulate incompressible Newtonian and non-Newtonian small Reynolds number flow through ducts with 1:3 sudden expansion for Reynolds numbers range from 40 to 140 solved by using the finite differences explicit Runge-Kutta time-stepping scheme. Power law model applied to predict shear-thinning and shearthickening behavior in expansions and made a comparison with an analytical solution. Abu-Mulaweh [4], reviewed a comprehensive of the flow and heat transfer results of laminar mixed convection flow over vertical, horizontal and inclined backward and forward-facing steps. Then he gave detailed summary of the effect of several parameters such as step height, Reynolds number and expansion ratio on temperature difference between the buoyancy force, the heated wall and the free stream and on the flow and thermal fields after the step. He reported several correlations to calculate the reattachment lengths of circulation regions. Oliveira [5] studied the flow of nonNewtonian liquids with constant shear viscosity through 1:3 symmetric sudden expansions. The considered geometry was planar. The constitutive model, which followed the modified FENE-CR equation, was valid to relative dilute solutions of polymeric fluids. For the nonNewtonian case, the transition depended on both the concentration and the extensibility parameters of the model, and the trend was for the pitchfork bifurcation to occur at higher Reynolds numbers. The given results comprised size and strength of the recirculation zones, and bifurcation diagrams. Poole et al. [6] [7] [8] made experimental study of back-word facing step for turbulent flow of thixotropic, shear thinning, and shear thickening liquids. They showed the effect on the reattachment length caused by variations in the maximum turbulence intensity at separation for expansion ratio 1.25 to 32 and aspect ratio 13.3. No major differences were found between the turbulent and mean flow characteristics of the Newtonian and non-Newtonian fluid flows. Neofytou [9] investigated numerically the effects on the threshold of transition between symmetry and asymmetry due to the flow through a 1:2 symmetrical sudden expansion by the attributes of generalized Newtonian fluids. The study included both shear thickening and shear-thinning fluids covering a range of the index $n$ of the Power-Law model from 0.3 to 3.0 with the use of the Casson model. Y1lmaz [10] studied numerically turbulent forced heat transfer for double contraction step flow. The bottom wall of the duct was heated by uniform temperature and the flow temperature of the stream core was colder than the wall. He employed the standard $\mathrm{k}-\varepsilon$ turbulence model to investigate turbulence flow modeling for double contraction step. The effect on heat transfer by Reynolds numbers, step heights and step lengths on and fluid flow was investigated. The second step could be used as a control device. Ternik et al. [11] studied numerically laminar incompressible nonNewtonian fluid flow through a symmetrical sudden expansion to calculate Reynolds number critical value. Lowers the onset of the bifurcation at the critical value of the Reynolds number and increased the reattachment length. The results for the Quadratic model was compared to the results obtained with the Power law.

This field has many effected parameters. Some of them are recording to the fluid type like viscosity, density and power law index. Another depend on the geometry dimension ratios such as expansion ratio, aspect ratio, and step ratio. However, other parameters depend on the inlet flow variable as velocity value and profile and turbulence intensity. All these parameters will effect in friction coefficient and the reattachment length.

\section{PROBLEM DESCRIPTION:}

The geometry that simulated is a rectangular channel with (Hin) height and (W) depth. This channel is twice expanded which are called the first step and the second step. Each expansion is in both sides: the upper and lower. The height of the upper and lower at first expansion is (h1) for each and the height of second is (h2). Therefore, the expansion ratio of the first step is $(\mathrm{Hin}+2 \mathrm{~h} 1) / \mathrm{Hin}$ and the expansion ratio of the second step is $(\mathrm{Hin}+2 \mathrm{~h} 1+2 \mathrm{~h} 2) /(\mathrm{Hin}+2 \mathrm{~h} 1)$ so the overall expansion ratio is $(\mathrm{Hin}+2 \mathrm{~h} 1+2 \mathrm{~h} 2) / \mathrm{Hin}$. The height of the first step is equal to the second $(\mathrm{h} 1=\mathrm{h} 2=\mathrm{h})$. The outlet has the same depth but different height (Hout) which is equal to (Hin $+4 \mathrm{~h})$. Each expansion is expanded with angle ( $\square 1$ and $\square 2$ respectively). The expansion angle of first step equals the second ( $\square 1=\square 2=\square$ ). The length of inlet (Lin) approach to zero so it is negligible. The distance between the first expansion edge and the second expansion edge is called the step distance (s). In other hand, the length of downstream channel (L) is variant with expansion ratio and step distance to verify the fully development length (L>10Hout) and gives the same lower wall area. The lower wall consist of two parts: first part that is between the first step and second step and second part that is from the second step to outlet. The total area of the lower wall is $\mathrm{W}(\mathrm{s}+\mathrm{L})$. The origin point leis at the center of edges of first expansion plane. All walls are isolated except the lower wall as in fig. 1.

Fig. 2 shows the regions of the flow structure and specifies some of the lines, curves and regions identifiers. The edge of step represents the line that connects the horizontal plane before step with the angled expansion plane of step. The reattachment curve of step represent the isocurve which velocity is zero at the wall boundary at the lengthdepth plane. The core of stream represents the part of flow that has no circulation. Circulation region represents the region in which the flow is flowing in closed curve. Zerovelocity curve represent the isocurve with velocity equals zero that separates between the circulation region and the core of stream. 
To generalize this geometry, the dimensionless scales most be used. The step height (h) is used to this job. Therefore, the length direction distance (xr) comes from the division of the length distance $(\mathrm{x})$ over the step height (h) also (yr) and (zr). Other ratios are taken to the max value of direction such as the aspect, expansion and step ratio. The aspect ratio (AR) is the ratio between the depth (W) and inlet height (Hin). The expansion ratio (ER) is the ratio between the outlet length (Hout) and the inlet height (Hin). The step ratio (SR) is the ratio between the distance between steps (s) and the step height (h).

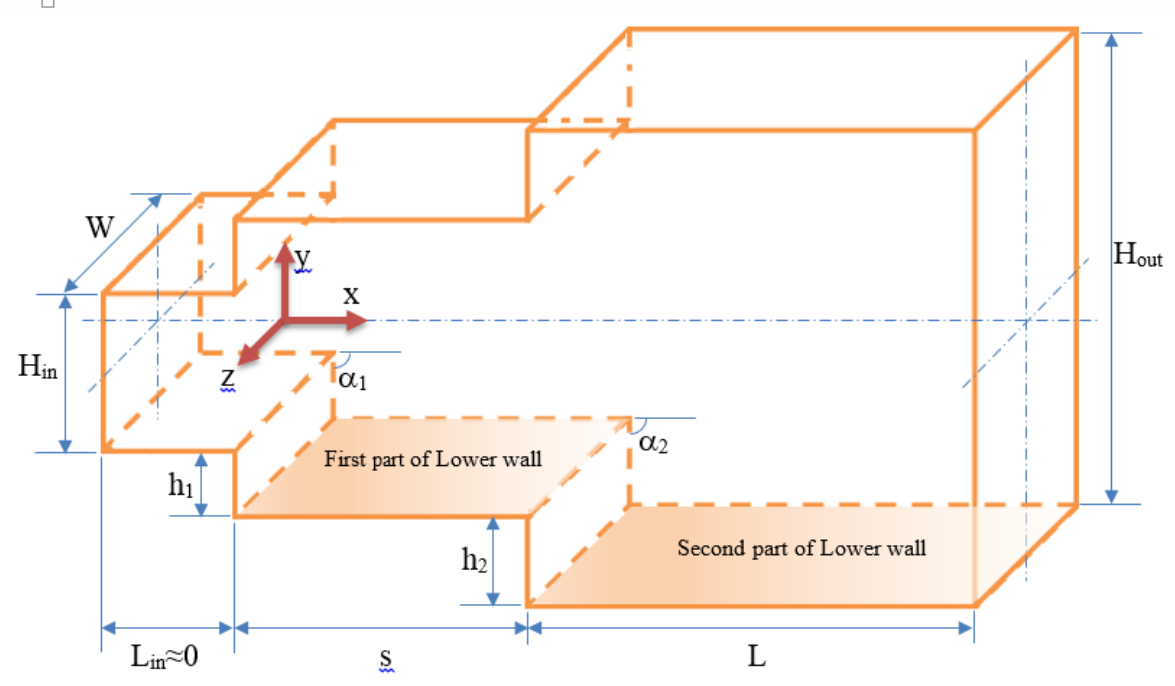

Figure 1 The geometry of the simulated case

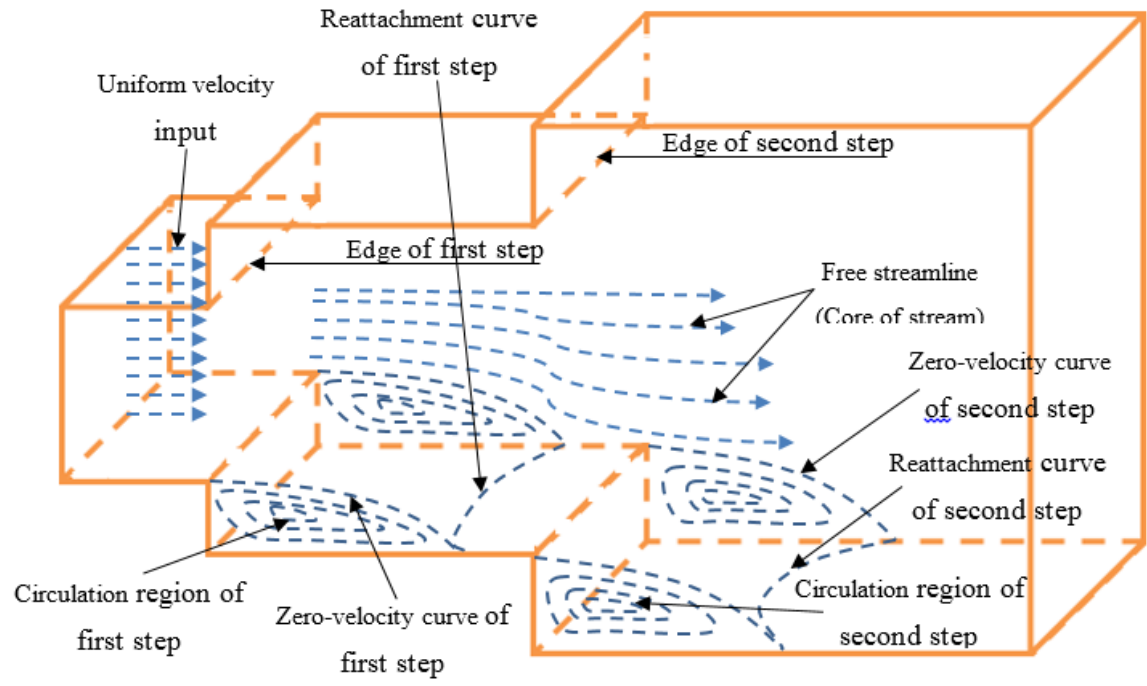

Figure 2 The lines and regions of the flow structure for the general structure

TABLE I . THE IMPORTANT STUDIED PARAMETERS

\begin{tabular}{ll}
\hline Parameter & Range \\
\hline Reynolds number (Re) & $16000-100000$ \\
\hline Power law index (n) & $0.4-1.6$ \\
\hline Expansion Ratio (ER=D/D) & $1.5-3$ \\
\hline Step ratio (SR=S/h) & $1-6$ \\
\hline Aspect ratio (AR=W/D) & $1-4$ \\
\hline
\end{tabular}

\section{Mathematical Model AND NuMerical}

\section{ANALYSIS:}

The fluids are assumed incompressible and viscous dissipation is neglected. The governing equations of the flow are depicted as follows:

Continuity equations

$\frac{\partial \rho u_{i}}{\partial x_{i}}=0$

Momentum equations 


$$
\begin{array}{r}
\frac{\partial \rho u_{i}}{\partial t}+\frac{\partial}{\partial x_{j}}\left(\rho u_{i} u_{j}\right)=- \\
\frac{\partial p}{\partial x_{i}}+\frac{\partial\left(-\overline{u_{i} u_{j}}\right)}{\partial x_{j}} \\
+\mu \frac{\partial^{2} u_{i}}{\partial x_{i}^{2}}-f_{i}
\end{array}
$$

\section{A. The Power-law fluid:}

The power law model covers the shear thinning or shear thickening behavior of materials.

$\sigma=K \dot{\gamma}^{n}$

Where $\mathrm{n}$ is the Power-law index or shear index, and $\mathrm{K}$ is the consistency factor [10] [11].

The viscosity in power law model is expressed as $\mu=\tau_{i j} / \dot{\gamma}_{i j}$

\section{B. The k- $\varepsilon$ model}

The turbulent kinetic energy and the dissipation at turbulent kinetic energy are represented by two transport equations as below [12]:

$$
\begin{aligned}
\frac{\partial \rho k}{\partial t}+\frac{\partial}{\partial x_{j}}\left(\rho k u_{j}\right)= & -\overline{u_{i} u_{j}} \frac{\partial u_{i}}{\partial x_{j}}-\rho \varepsilon \\
& +\frac{\partial}{\partial x_{j}}\left\{\left(\frac{v_{t}}{\sigma_{k}}+\mu\right) \frac{\partial k}{\partial x_{j}}\right\}+c_{f k} G_{v} \\
\frac{\partial \rho \varepsilon}{\partial t}+\frac{\partial}{\partial x_{j}}\left(\rho \varepsilon u_{j}\right)= & -c_{\varepsilon 1} \frac{\varepsilon}{k} \overline{u_{i} u_{j}} \frac{\partial u_{i}}{\partial x_{j}}-c_{\varepsilon 2} \rho \frac{\varepsilon^{2}}{k} \\
& +\frac{\partial}{\partial x_{j}}\left\{\left(\frac{v_{t}}{\sigma_{\varepsilon}}+\mu\right) \frac{\partial \varepsilon}{\partial x_{j}}\right\}+c_{\varepsilon 2} c_{f s} \frac{\varepsilon}{k} G_{v}
\end{aligned}
$$

\section{Boundary Conditions:}

Since all Computational fluid dynamics problems are defined in terms of boundary conditions and initial conditions, knowledge of these conditions is essential for the quality and accuracy of the obtained solution. The double step expansion contains the following boundary zones: walls, inlet, outlet boundary.

\section{i. Inlet boundary conditions}

The distribution of all flow variables needs to be specified at the normal to the inlet of the double step expansion channel. The whole inlet flow entering the channel is supplied through a channel with $\mathrm{H}_{\text {in }} \times \mathrm{W}$ dimensions as the inlet boundary. The most appropriate boundary condition is the velocity profile. A uniform inlet velocity profile is applied. This velocity is varied according to a specific Reynolds numbers (4000, 16000, 40000 and 100000) with initial value of turbulence intensity equals to $5 \%$.

\section{ii. Wall boundary conditions}

All velocity components close to a wall will reach zero velocity. The no-slip boundary condition is used to perform zero velocity at solid walls.

$$
u=v=w=0
$$

Moreover, turbulence properties have to be specified at walls. Since the no-slip condition is valid, the turbulent kinetic energy remains zero.

$$
k=0
$$

All walls are isolated except the lower wall has a constant heat flux.

$$
\left.\frac{\partial T}{\partial y}\right|_{\text {upper }}=0 \text { at }(0<\mathrm{x}<\mathrm{s} \text { and } \mathrm{y}=\mathrm{Hin} / 2+\mathrm{h}) \text { or }(\mathrm{s}<\mathrm{x}<\mathrm{L}
$$

and $\mathrm{y}=\mathrm{Hin} / 2+2 \mathrm{~h})$

$$
\begin{aligned}
& \left.\frac{\partial T}{\partial z}\right|_{\text {side }}=0 \text { at }(0<\mathrm{x}<\mathrm{L} \text { and } \mathrm{y}= \pm \mathrm{W} / 2) \\
& \left.\frac{\partial T}{\partial y}\right|_{\text {lower }}=\text { Const. } \text { at }(0<\mathrm{x}<\mathrm{s} \text { and } \mathrm{y}=-\mathrm{Hin} / 2-\mathrm{h}) \text { or }
\end{aligned}
$$

$(\mathrm{s}<\mathrm{x}<\mathrm{L}$ and $\mathrm{y}=-\mathrm{Hin} / 2-2 \mathrm{~h})$

The standard wall function is used.

\section{iii. Outlet boundary conditions}

The zero relative pressure outlet represents the outlet boundary without smoothing exit boundary to get the maximum turbulence intensity. As in the following equation:

$$
\Delta p=0 \text { at } x=L
$$

The governing flow and transport turbulence equations are discretized on non-uniform mesh of different densities. Constricting the mesh was done by a Gambit 2.4 and ANSYS fluent 15.0 adopted for solution these discretized equations.

\section{Grid independency:}

To avoid the mesh effect on studied parameters, a different number of mesh are tested for each geometry case. This 
test prove that each case needs different number of mesh because Reynolds number and expansion ratio effect.

Each Reynolds needs different number of meshes and for the same Reynolds number; the higher power law index needs more iterations to converge.

Figure 3 illustrate the changing of the calculated reattachment length value for different height of step divisions at low and medium Reynolds number. The reattachment length not like friction coefficient that depends on the $\mathrm{x}, \mathrm{y}$ and $\mathrm{z}$ divisions. The reattachment length depends on $\mathrm{x}$ and $\mathrm{y}$ divisions only and generally on $\mathrm{y}$ divisions so can adapt the mesh in this direction or the near wall mesh to give a good accuracy. The best accuracy as in the figure and the table at division $(\mathrm{h} / 20)$ and greater.

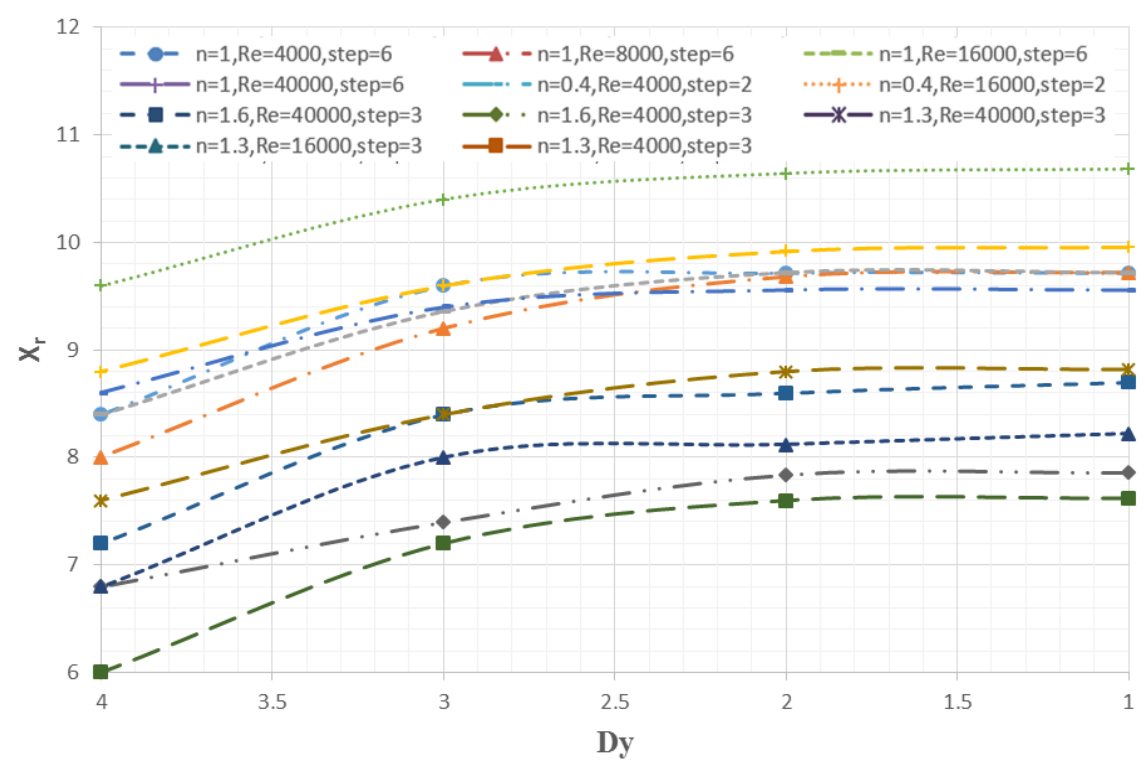

Figure 3 The reattachment length changing with reducing of the height divisions

\section{RESULTS AND DISCUSSION:}

\section{A. Verification}

To approve the model of the present work, two past works are chosen. The first work by Poole et al. (2003) [6]. The basic local values used to compare is the velocity profile. In addition, it is good to compare the average of local values in each plain in three-dimension simulation. Therefore, we compare the reattachment length; pressure coefficient and friction coefficient after describe the geometry and the used fluids of each work.
Figure 4 illustrates the velocity profile of $0.01 \%$ polyacrylamide solution after expansion for different Reynolds number with the simulated results. The root mean square error (RMSE) equal to $3.41 \%$. It can be noticed that simulation gives a good agreement between the measured and simulated results are obtained.

These results prove that the power law with $k-\varepsilon$ model can give a beneficial accepted data to simulate the non-newtonian turbulent flow through expansion channel. 

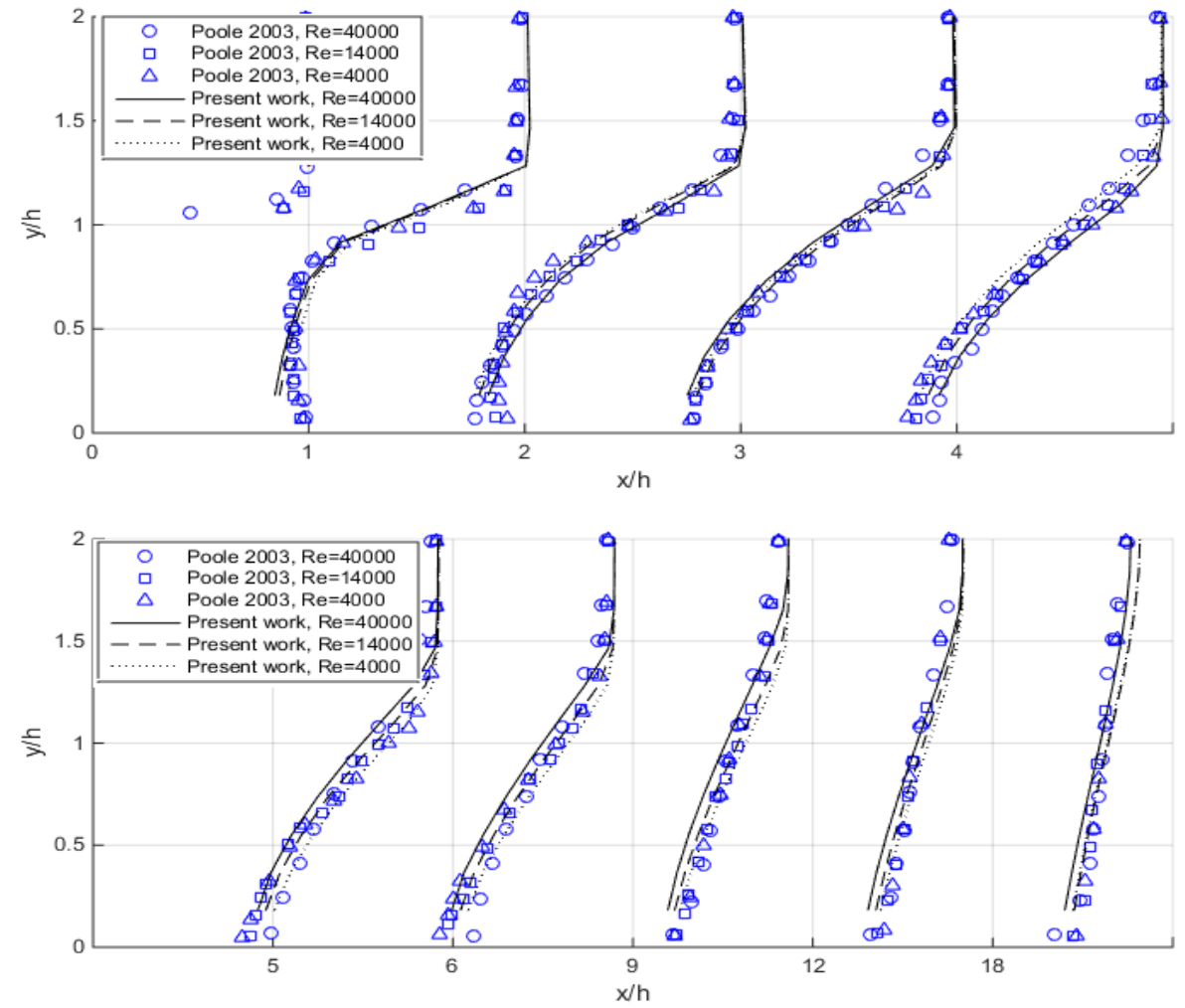

Figure 4 Velocity profile along stream after expansion for the first work, $n=0.858 \& \operatorname{Re}=4000,14000$ and 40000 .

RMSE $=3.41 \%$.

\section{B. Velocity contour}

To declare the 3D velocity changing through the channel, the contour representation is good to illustrate it.

Figure 5 and 6 illustrate the velocity contour of the first expansion in 6 sections: at $\mathrm{x}_{\mathrm{r}}(\mathrm{x} / \mathrm{h})$ equals $1,2,3,4,5$ and 6. At $\left(\mathrm{x}_{\mathrm{r}}=1\right)$, there are four concentrical contour curves: two represent peaks and two represent bottoms. The two bottoms appear at upper and lower sides. They represent the upper and lower negative velocity (reverse flow regions). The two peaks appear in the core of stream. These peaks appear due to the conversion of the uniform velocity profile to sudden expansion profile because of the size of circulation regions on both sides a little narrow the path of core stream. These peaks will disappear gradually after expansion. This distribution continues in the same way at $\mathrm{xr}=5$ but the two bottoms convert to four bottoms at the corner of expansion because the circulation region end near center and stay at the corners only and the two peaks merge in one.
The second expansion region is illustrated in figure 6. It is also divided to 6 sections: $x r$ equals 7. At $\mathrm{xr}=7$, this contour combines from three concentrical contour curves: one peak and two bottoms. Each bottom has two sub-concentrical contour curves that represent the negative velocity of corners. The corners effect appears earlier than in first expansion because of the non-uniform velocity in the beginning of second expansion. In addition, the asymmetric also begins earlier because of the bigger bifurcation. This bifurcation continues in the other sections and it is clear at the peak of stream core at $\mathrm{xr}=9$ from the inner contour curve shape. All these sections have a deflected stream core to the lower side.

The only effecting parameter is the fully developed effect due to shear stress. Therefore, this plane will be symmetric. Most of the contour curves in all sections convert to parallel straight lines at the downstream because they reach near the fully developed length. 

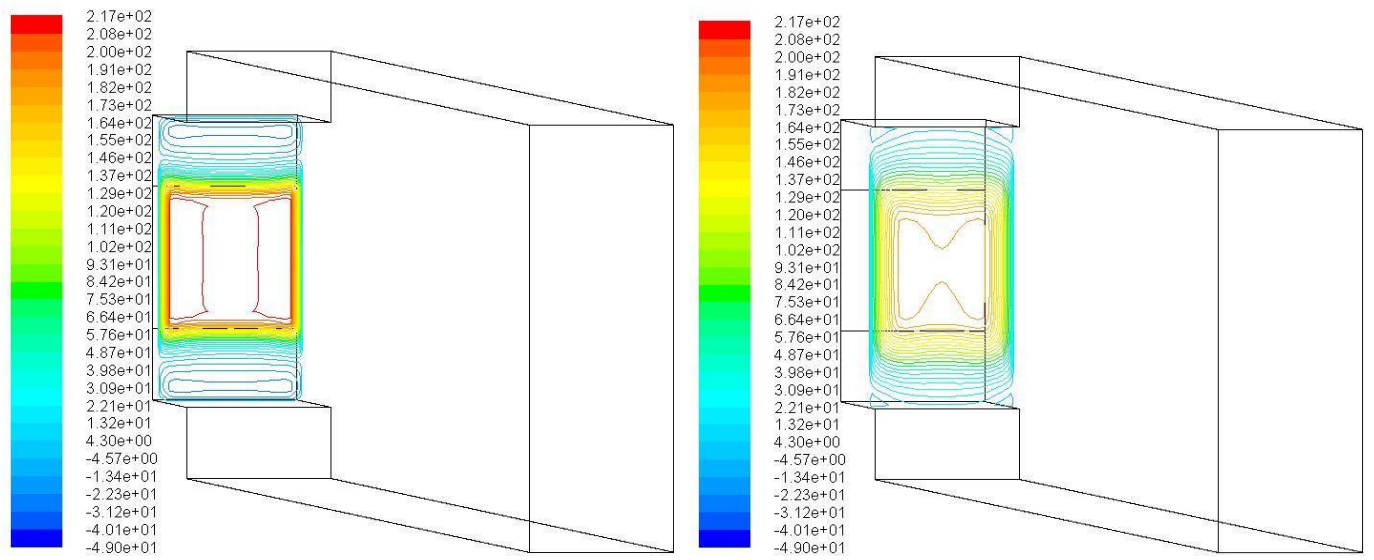

Figure 5 3D velocity contour of $\operatorname{Re}=4000$ and $E R=3$ for $x r=1$ and 6
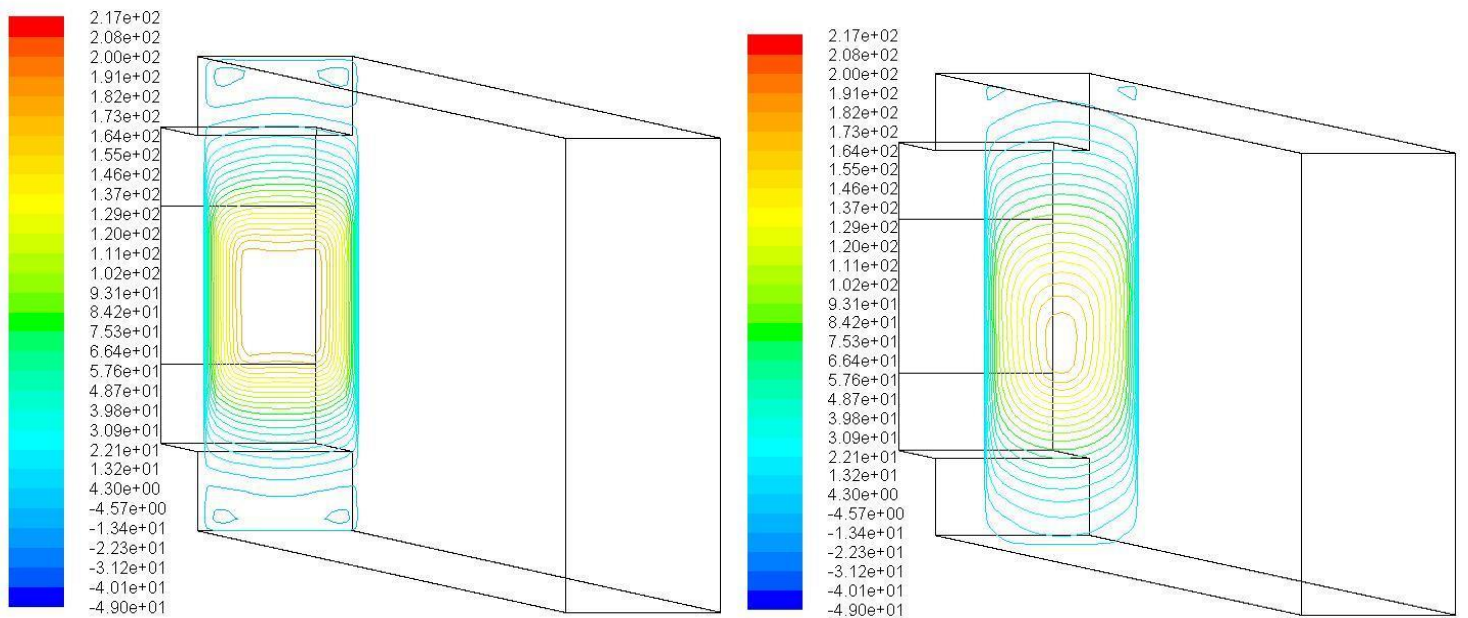

Figure 6 3D velocity contour of $R e=4000$ and $E R=3$ for $x r=7$ and 9

\section{Effect of step ratio}

The most important parameter in this study is the step ratio because has the ability to change the flow structure strongly. Therefore, it has strong effect on the variables that directly depend on geometry but less effect on the variable that directly depend on velocity magnitude.

\section{a. Effect of step ratio on reattachment length}

Figure 7,8 and 9 show the reattachment length for the isocurve of Reynolds number. Figure 7 represents the behavior of the reattachment length of shear thinning fluids. It is clearing up that the reattachment length in the indirect interaction increasing in the same rate for all Reynolds number. In addition, figure 8 which represents the Newtonian fluids shows similar behavior but not for the low Reynolds number $(\operatorname{Re}=4000)$. However, in figure
9, this behavior is not exist. The reattachment length reverses its increasing and the less Reynolds number will be higher in reattachment length. All this behavior occurs because the step ratio controls what type of interaction will occur. Therefore, when it will be increase the circulation region will deform and be smaller. This will reduce the reattachment length until it reaches to separation region then the reattachment length will increase linearly with step ratio. For each power law index, there is a critical value of step ratio after it the separation occurs. This critical value increase with Reynolds number.

In general, when take the reattachment length as a ratio to the reattachment length of single step expansion $(\mathrm{SR}=0)$, it clears that the ratio of the reattachment length it always less than 1 but when the indirect interaction begins 
the ratio increases and it can be greater than 1 as in figure 4-38.

\section{b. Effect of step ratio on Nusselt number}

Figure 10, 11 and 12 show clearly that the Nusselt number at indirect interaction less than Nusselt number at the direct interaction and in range less than 4 (direct interaction), Nusselt number is not changing. The Nusselt number depends on the size of the outer circle of the circulation region. Therefore, one big circle makes more mixing from two-separated regions. The same outer circulation of the different type of direct interaction gives same Nusselt number. Therefore, the relative Nusselt number always near 1 in the range from 1 to 4 and less than 1 for step ratio greater than 4 . The Nusselt number depends generally on velocity and the size of outer circulation.

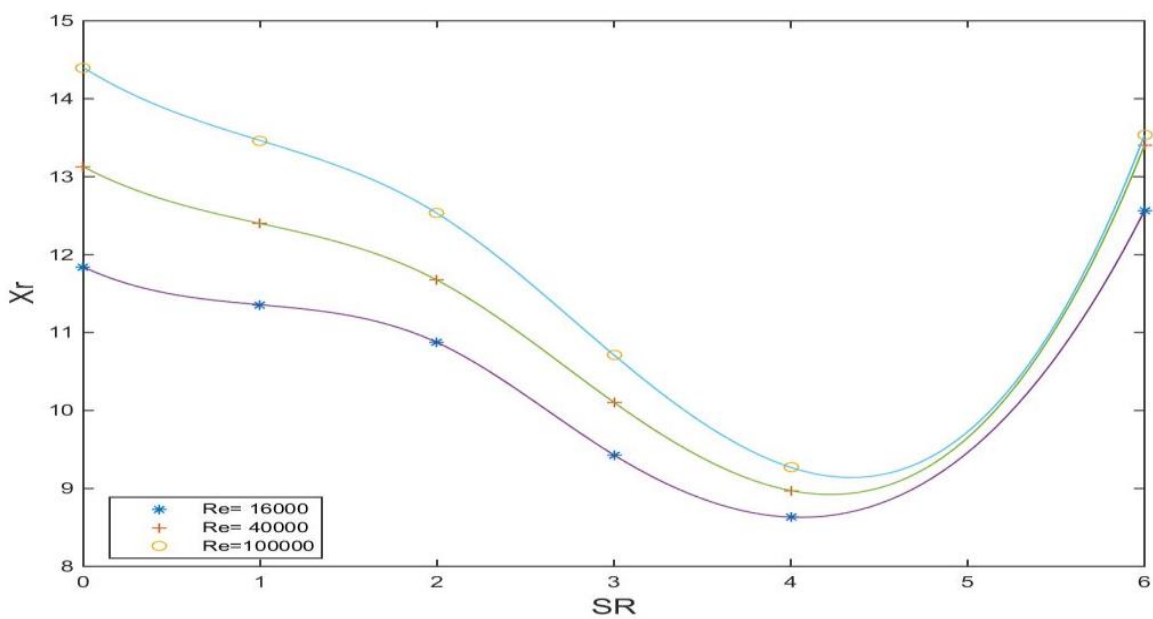

Figure 7 The reattachment length with the step ratio for $\mathrm{n}=0.4, \mathrm{EA}=90^{\circ}, \mathrm{ER}=1.5$ and $\mathrm{AR}=1$.

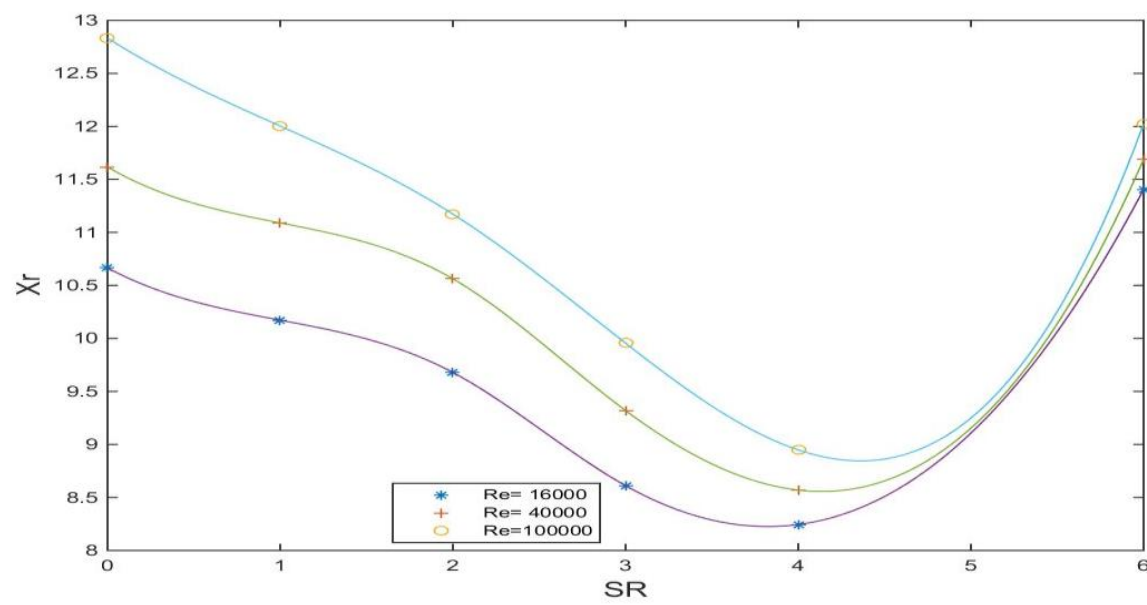

Figure 8 The reattachment length with the step ratio for $n=1, E A=90^{\circ}, E R=1.5$ and $A R=1$. 


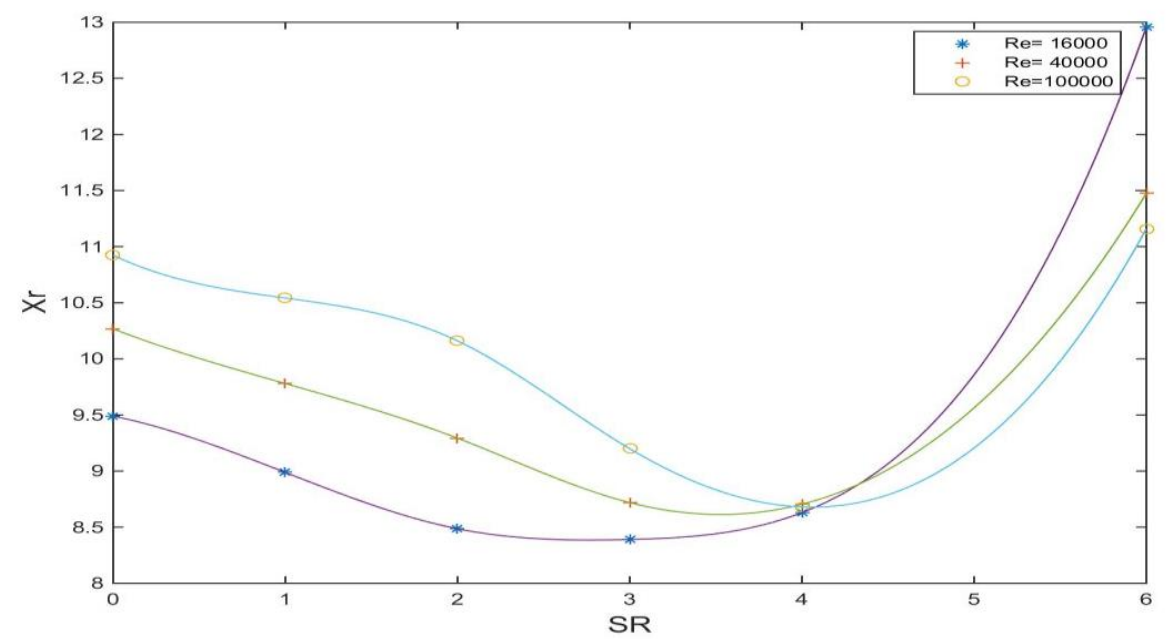

Figure 9 The reattachment length with the step ratio for $n=1.6, E A=90^{\circ}, E R=1.5$ and $A R=1$.

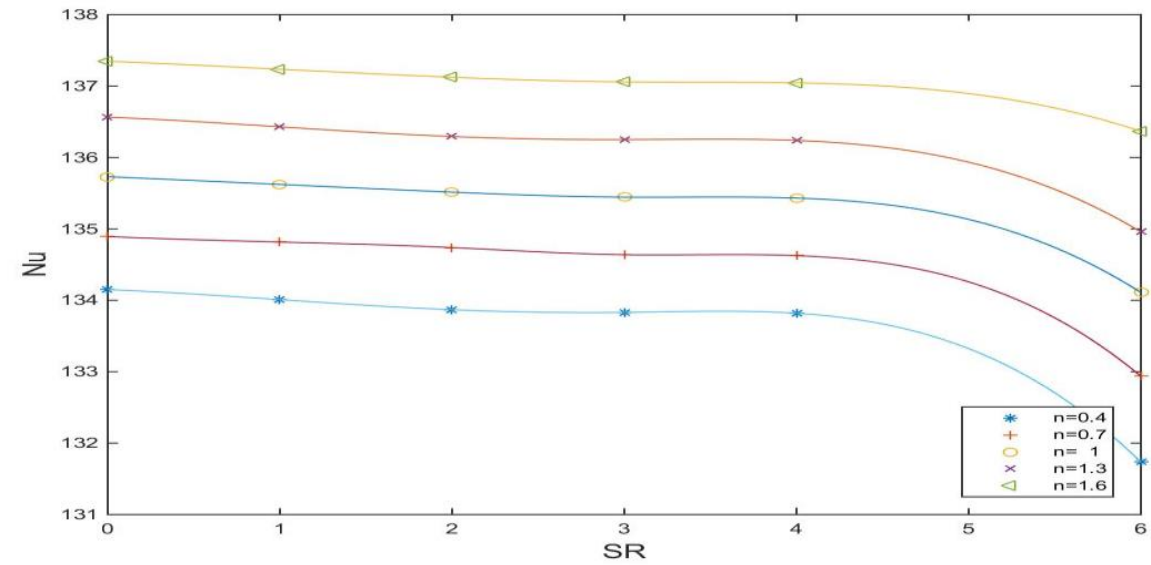

Figure 10 the nusselt number with the step ratio for $\mathrm{Re}=4000, \mathrm{EA}=\mathbf{9 0}^{\circ}, \mathrm{ER}=1.5$ and $\mathrm{AR}=1$.

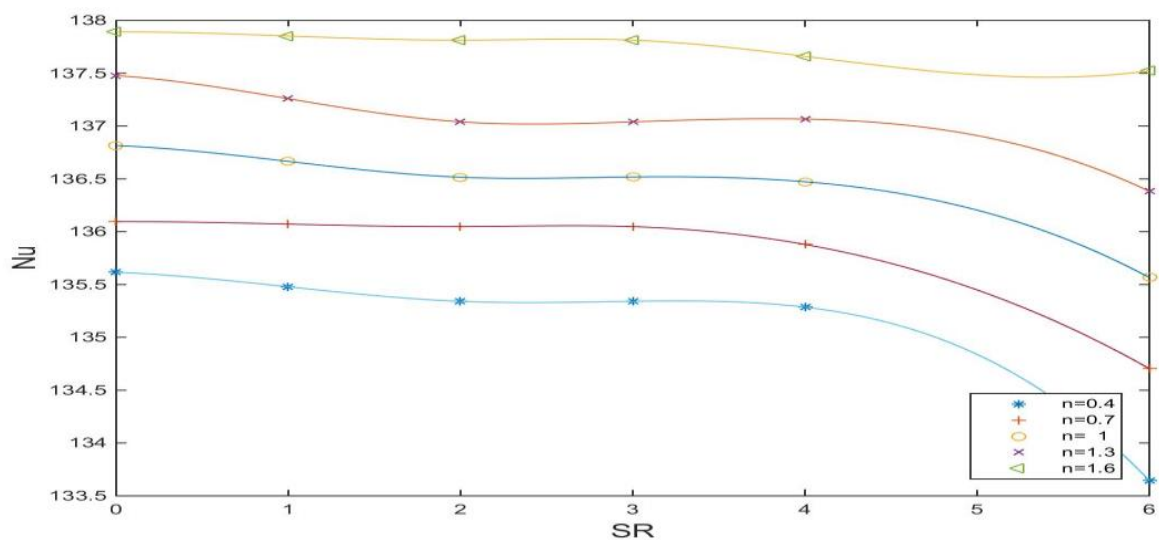

Figure 11 the nusselt number with the step ratio for $\mathrm{Re}=16000, \mathrm{EA}=90^{\circ}, \mathrm{ER}=1.5$ and $\mathrm{AR}=1$. 


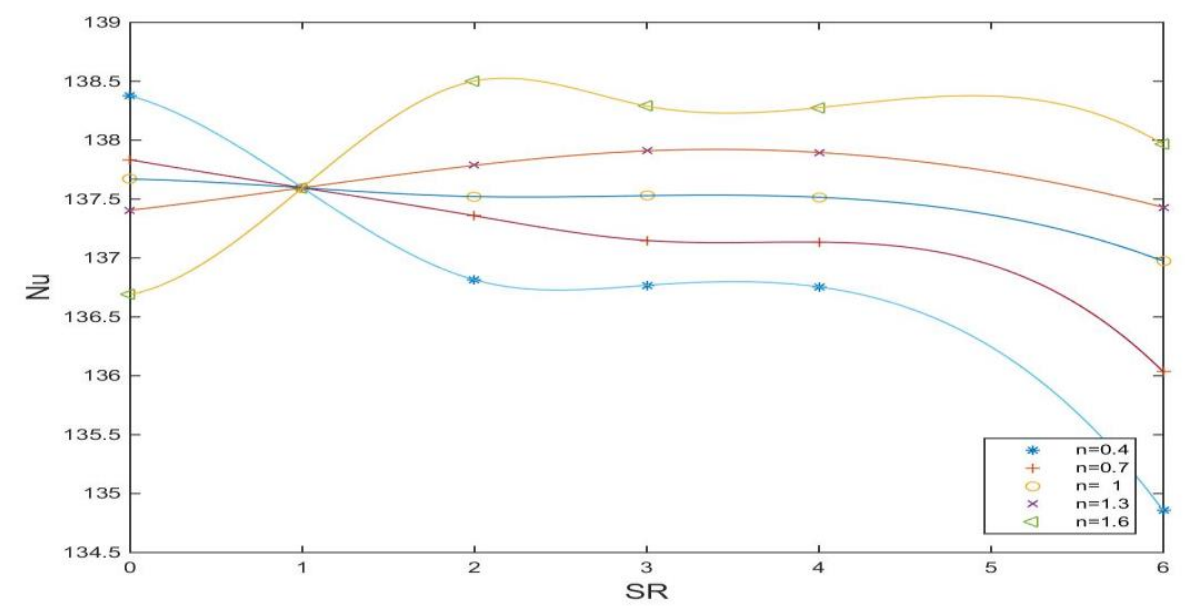

Figure 12 the nusselt number with the step ratio for $\mathrm{Re}=40000, \mathrm{EA}=\mathbf{9 0 ^ { \circ }}, \mathrm{ER}=1.5$ and $\mathrm{AR}=1$.

\section{CUNCLUSION:}

From the presented results and discussion, we can light some points. These points can be as conclusions of this thesis. These conclusions order as like as it comes in the results.

- The step ratio value specifies the type of interaction that will be occurring.

- In double step, the bifurcation happens at expansion ratio equals 3 .

- In turbulent flow, there is no critical Reynolds number to occur the bifurcation phenomenon.

- Reattachment length of the second step is less than of the first step.

- The maximum uniform turbulence intensity distribution occurs before the fully development length near seven times of the outlet diameter.

\section{REFERENCES}

[1] D. K. Mandal, S. Bandyopadhyay and S. Chakrabarti, "A numerical study on the flow through a plane symmetric sudden expansion with a fence viewed as a diffuser," MultiCraft International Journal of Engineering, Science and Technology, vol. 3, no. 8, pp. 210-233, 2011.

[2] A. K. Podolsak, C. Tiu and T. N. Fang, "Flow of nonNewtonian fluids through tubes with abrupt expansions and contractions (square wave tubes)," J. Non-Newtonian Fluid Mech., no. 71, pp. 25-39, 1997.

[3] R. Manica and A. L. de Bortoli, "Simulation of Incompressible Non-Newtonian Flows Through Channels with Sudden Expansion Using the Power-Law Model," TEMA Tend. Mat. Apl. Comput., vol. 4, no. 3, pp. 333340, 2003.

[4] H. I. Abu-Mulaweh, "A review of research on laminar mixed convection flow over backward- and forwardfacing steps," International Journal of Thermal Sciences, no. 42 , p. 897-909, 2003.

[5] P. J. Oliveira, "Asymmetric flows of viscoelastic fluids in symmetric planar expansion geometries," J. NonNewtonian Fluid Mech., no. 114, p. 33-63, 2003.
[6] R. J. Poole and M. P. Escudier, "Turbulent flow of non-Newtonian liquids over a backward-facing step," J. Non-Newtonian Fluid Mech., no. 109, p. 177-191, 2003.

[7] R. J. Poole and M. P. Escudier, "Turbulent flow of viscoelastic liquids through an axisymmetric sudden expansion," J. Non-Newtonian Fluid Mech., no. 117, p. 25-46, 2004.

[8] R. J. Poole, F. T. Pinho, M. A. Alvesc and P. J. Oliveira, "The effect of expansion ratio for creeping expansion flows of UCM fluids," J. Non-Newtonian Fluid Mech., no. doi:10.1016/j.jnnfm.2009.06.004, 2009.

[9] P. S. B. Zdanski, M. V. Jr. and A. P. Dias, "POLYMER MELT FLOW IN SUDDEN EXPANSIONS: THE EFFECTS OF VISCOUS HEATING," Engenharia Térmica (Thermal Engineering), vol. 7, no. 1, pp. 65-70, 2008.

[10] P. S. B. Zdanski and M. V. Jr., "Three-dimensional polymer melt flow in sudden expansions: Non-isothermal flow topology," International Journal of Heat and Mass Transfer, no. 52, p. 3585-3594, 2009.

[11] P. C. Sousa, P. M. Coelho, M. S. N. Oliveira and M. A. Alves, "Three-dimensional flow of Newtonian and Boger fluids in square-square contractions," J. NonNewtonian Fluid Mech., no. 160, p. 122-139, 2009.

[12] Q. A. Rishack, K. S. Mushatet and A. A. Ouda, " Investigation of Non-Newtonian Fluids Flow Behavior in a Double Step Expansion Channel:Part 1," ijert, vol. 5, no. 8, pp. 160-168, 2016. 